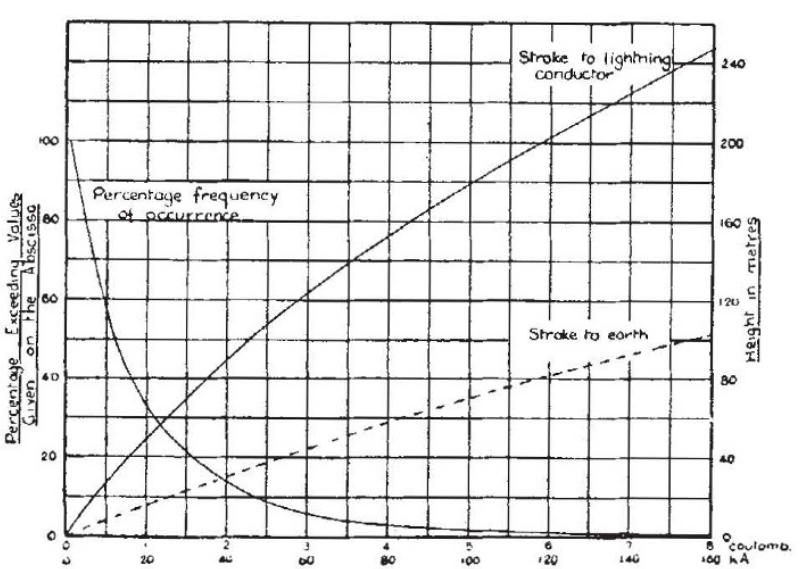

Fig. 1. HEIGHT OF TIP OF LEADER STROKE AT INSTANT AT WHich UPWARD STREAMER MAY DEVELOY

streamers is rendered difficult by the halation produced by the heavy return stroke.

I am therefore greatly indebted to Dr. D. J. Malan, of the Bernard Price Institute, Johannesburg, South Africa, for having supplied me with a most interesting account of an upward streamer ${ }^{2}$, and for his permission to use the information given. The sketch reproduced in Fig. 2 shows the earth terminal of a stroke which occurred on flat bare country at a distance of about $2 \mathrm{~km}$. from the camera. The record was obtained with one lens of the Boys' camera stopped down, and this alone prevented the base of the main discharge channel being blurred by the return stroke. As can be seen in Dr. Malan's sketch, the ultimate step of the leader goes down to $X$, where it becomes 'ground conscious' and joins the main return channel. The height of $X$ is of the order of 50 metres.

Applying Fig. 1 to the foregoing case, the stroke may be expected to have discharged a current amplitude of about 60-70 kiloamperes, a value which is exceeded in 5 per cent only of all discharges. Thus the only photograph which has been taken in South Africa under suitable conditions shows the presence of a pronounced streamer, and the theoretical value of the current amplitude agrees with Dr. Malan's comment that the current involved was believed to be of more than average intensity - the two estimates having been made independently and being based on entirely different considerations.

'Two other relevant photographs have been taken in the United States, on beaches in New Jersey and near Pittsfield respectively. The first photograph ${ }^{3}$ shows a pronounced upward streamer of about 3 metres length. From Fig. 1 the current intensity

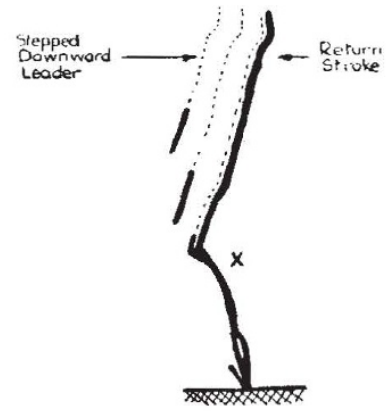

Fig. 2, SKETCK OF LOWER END OF A BOYS' OAMLRA RECORD of this stroke would be estimated at 7 kiloamperes. That this stroke was, in fact, of exceptionally low intensity is strongly indicated by the absence of halation of the photograph, which was taken at a distance of only $100 \mathrm{ft}$. from the discharge.

The second case ${ }^{4}$, which has just been reported, is not so clear, but is described as a discharge channel which is split from a height of about $1 \cdot 3$ metres to 12.5 metres above the shore. If this is due to an upward streamer, it suggests a current amplitude of the order of 20-30 kiloamperes. That this discharge was not of high intensity appears to be borne out by the observation that no upward streamer could be detected from two tall smoke-stacks about $400 \mathrm{ft}$. distant.

More observational evidence on this phenomenon is greatly to be desired.

British Electrical and Alliod Industrios

R. H. Golde

Research Association,

5 Wadsworth Road, Greenford, Middlesex.

June 17.

1 Golde, R. H., Trans. Amer. Inst. Elect. Eng., 64, 902 (1945).

Malan, D. J., and Collens, H., Proc. Roy. Soc., A, 162, 175 (1837) Fig. 17 (ii).

McEachron, K. B., and Morris, W. A., Gen. Elect. Rev., 39, 487 (1936).

- Hagenguth, J. H., Proc. Amer. Inst. Elect. Eng., 66, 798 (1947).

\section{Temperature Coefficient of Rotation of Quartz in the Ultra-Violet Region}

IN the course of work on the optical constants of metals using an apparatus designed by one of us (A. M. T.), and constructed with the aid of grants from the Carnegie Trust and Royal Society, it became necessary to have an estimate of the temperature coefficient of rotation of quartz in the ultra-violet. (The rotation at temperature $T_{2}^{\circ} \mathrm{C}$. may be expressed by $\rho_{2}=\rho_{1}\left\{1+\alpha\left(T_{2}-T_{1}\right)\right\}$, where $\rho_{2}$ is the rotation at $T_{2}^{\circ} \mathrm{C}$. and $\rho_{1}$ the rotation at temperature $T_{1}{ }^{\circ}$ C.) A search of the literature only yielded a coefficient for the visible spectrum. It was therefore decided to make an estimate using the apparatus itself.

At $2536 \mathrm{~A}$. it was found that a change in temperature of the quartz windows from $18^{\circ} \mathrm{C}$. to $32^{\circ} \mathrm{C}$. produced a change in rotation of $4.9^{\circ}$ for a total rotation due to the windows of $2,371^{\circ}$. This gives a value of the coefficient at $2536 \mathrm{~A}$. of $1.46 \times 10^{-4}$ with an estimated accuracy of \pm 2 per cent. At $3650 \mathrm{~A}$. the change was $2 \cdot 0^{\circ}$ for a total rotation of $984^{\circ}$, giving $1.45 \times 10^{-4}$ as the value of the coefficient, with an estimated accuracy of \pm 4 per cent. Values obtained at other wave-lengths were consistent with a value of $1.44 \times 10^{-4}$, allowance being made for the decreasing accuracy of measurement, as the change in rotation decreases with increasing wave. length.

The value of the temperature coefficient in the visible ${ }^{1}$ is $1.44 \times 10^{-4}$. Our estimate of this coefficient in the ultra-violet therefore suggests that the temperature coefficient of rotation of quartz at room temperature is constant from the visible into the ultra-violet.

University College,
Southampton.

A. W. Crook June 13.

1 "Int. Crit. Tables", 2, 336. 